Годованюк П. Д.

Національний транспортний університет, Київ, Украӥна

\title{
МАТЕМАТИЧНА МОДЕЛЬ ПРОГНОЗУВАННЯ ПОПИТУ НА АВТОСЕРВІСНІ ПОСЛУГИ
}

\footnotetext{
У роботі запропонована методика складання математичної моделі прогнозування попиту на автосервісні послуги.

Розробка відповідних моделей є важливим завданням. При розробці були враховані наступні фактори:

- можлива зміна загальної кількості автомобілів $N_{a в m}$, що знаходяться в зоні ділової активності СТО;

- інтенсивність експлуатації, тобто середньорічний пробіг $\bar{L}_{P}$ автомобілів, що знаходяться в даному регіоні, а також динаміку його зміни по різних періодах року $(j)$;

- середні напрацювання $\bar{I}_{j}$ на один автомобиле-заїзд на СТО;

- можлива зміна частки ринку $K_{j}$, що займає це підприємство в районі ділової активності;

- частка власників $\alpha$, які звертаються на СТО.

Комплексне врахування перелічених вище факторів дозволяє виконати прогнозування зміни $\bar{N}$

середньодобової кількості звернень ${ }_{\text {дj }}$ по різних видах робіт $(i)$, з урахуванням його сезонності $(j)$

3 метою спрощення отримуваної моделі, а також 3 урахуванням короткострокового періоду прогнозування, без втрати точності отримуваного результату, були прийняті постійні наступні величини:

- середньорічний пробіг $\bar{L}_{P}$;

- коефіцієнт, що враховує динаміку посезонної зміни середнього річного пробігу $-K_{\text {дj; }}$

- долю власників, що користуються послугами СТО в цьому регіоні $\alpha$;

- режим роботи СТО, що визначається кількістю днів роботи $D_{p}$ підприємства на даних періодах року;$$
\overline{t_{1}}
$$

$\bar{t}_{13 в . i j}$ - середню трудомісткість одного звернення.

Таким чином, прогнозування попиту на послуги СТО зводиться до оцінки зміни середньодобової кількості звернень на СТО, для чого була розглянута динаміка зміни його складових (1). У загальному вигляді, методика прогнозування попиту на послуги СТО, визначається середньодобовою кількістю звернень на СТО, та включає п'ять етапів.

Недоліком використання цього методу є те, що пропадають, відповідно, одна або дві, відповідно, перші i останні точки даного часового ряду. Для їх визначення використовуються наступні вирази: для ковзного середнього по трьох точках - вирази (17) і (18), для ковзного середнього по п’яти точках - формули (19)-(20), відповідно [1, с. 90]:

Ключові слова:, автосервісні послуги, реконструкція, ефективність, математична модель, оптимізація.
}

\section{ВСТУП}

Вивчення ринку легкових автомобілів та ринку послуг з ремонту та технічного обслуговування дає можливість визначити вплив зовнішніх та внутрішніх змінних факторів на мету і задачі АСП. Для вирішення завдань забезпечення якісних послуг в АСП розроблено комплекс моделей ефективного функціонування виробництва, в яких поєднуються інтереси і споживачів і надавачів послуг. Оптимізація виробничих процесів впливає на якість послуг і забезпечує можливість отримання прибутку.

Запропонована математична модель прогнозування попиту в автосервісі є базою для розробки і реалізації проектів організаційного та управлінського характеру, що дасть можливість надавати конкурентоспроможні послуги та задовольняти потреби споживачів.

\section{АНАЛІЗ ЛІТЕРАТУРНИХ ДАНИХ ТА ПОСТАНОВКА ПРОБЛЕМИ}

Проблеми дослідження та визначення сучасного стану ринку послуг 3 технічного обслуговування і ремонту (ТО і Р) автотранспортних засобів (АТС) присвячено багато робіт, оскільки вони $є$ важливими характеристиками, які визначають його поведінку під впливом зовнішніх факторів. Відомо багато робіт вітчизняних вчених: 3.С. Варналія, Л.Л. Антонюка, Л.С. Шевченко, О.В. Зозульова, В.Г. Герасимчука, О.Л. Каніщенка, Ю.М. Лисенкова, А.А. Мазаракі проф. Сахно В.П., проф. Клепіков В.Б., проф. Павлов В.Б, доц. Сітовский О.П., доц. Дембіцький В.М., проф. Двадненко В.Я., проф. Туренко А.М., проф. Гнатов А.В., проф. Богомолов В.А., проф. Абрамчук Ф.І., проф. Бажинов А.В. і багато інших вчених. 
Рівень розвитку сфери послуг зазвичай чітко відображає економічний потенціал. Ї̈̈ розширення $\epsilon$ індикатором економічного зростання країни, бо збільшення значущості цієї сфери $є$ стимулом зростання реального сектору та попиту на продукцію. Проте збільшення кількості підприємств сфери послуг посилює конкуренцію між ними. А в умовах постійно зростаючих потреб споживачів забезпечення стійкої позиції на ринку та високого рівня конкурентоспроможності є невід’ємною умовою ефективної та прибуткової діяльності підприємства.

Ринок автосервісних послуг - це відносини між автовласниками і підприємствами системи автосервісу з приводу купівлі-продажу послуг, направлених на підтримку працездатності та відновлення автомобіля протягом всього терміну експлуатації.

Автосервісні послуги мають свої особливості, для них характерно непостійність якості. Поперше, до отримання послуги неможливо оцінити ії якість. Встановлюючи вимоги до якості послуг, неможливо провести будь-які контрольні вимірювання до ії̈ надання. Тільки після закінчення процесу виробництва послуги оцінка якості стає можливою. По-друге, послуги надаються людьми при взаємодії покупця і персоналу, які виконують замовлення. Отриманий результат залежить не тільки від персоналу, але і від їх спільних дій і сприйняття покупця, оскільки основна оцінка послуги - це індивідуальний погляд на ії корисність. По-третє, в силу різної кваліфікації персоналу одна і та ж послуга буде по-різному надана різними майстрами $\mathrm{i}$ різними фірмами. По-четверте, послуги диференційовані, тобто різними фірмами виконуються не тільки по-різному, але і в різному наборі індивідуально для кожного клієнта. Цей майстер може варіювати свої дії при кожному окремому виконанні послуги. По-п'яте, важливу роль відіграє фізичний і психологічний стан клієнта, яке змінюється і тягне за собою зміну оцінок задоволеності наданою послугою.

Головною ланкою системи автосервісу $\epsilon$ станції технічного обслуговування (СТО) підприємства, що здійснюють технічне обслуговування та ремонт автомобілів, продаж автомобілів, запасних частин і автомобільних аксесуарів.

Якість автосервісу за світовими стандартами складається 3: професійного технічного обслуговування і ремонту; доставки після ремонту; обслуговування точно в обіцяний день і годину; передбачає - розумні ціни за послуги, доброзичливе обслуговування замовників, ефективну, акуратну і швидку офісну роботу - оформлення замовлень, підготовку документації і т.д.

\section{ЦІЛЬ ТА ЗАДАЧІ ДОСЛІДЖЕННЯ}

Розробка методики складання математичної моделі прогнозування попиту на автосервісні послуги є актуальним завданням сьогодення. За допомогою якої, було б можливим ефективне планування різних заходів (реконструкції, технічного переозброєння і т.д.) 3 підвищення ефективності роботи станції технічного обслуговування (СТО)

\section{РЕЗУЛЬТАТИ ДОСЛІДЖЕНЬ}

Оскільки ефективне планування різних заходів (реконструкції, технічного переозброєння і т.д.) 3 підвищення ефективності роботи станції технічного обслуговування (СТО) неможливе без прогнозування попиту, розробка відповідних моделей $є$ важливим завданням. При розробці необхідно врахувати наступні фактори:

- можлива зміна загальної кількості автомобілів $N_{a в m}$, що знаходяться в зоні ділової активності CTO;

- інтенсивність експлуатації, тобто середньорічний пробіг $\bar{L}_{P}$ автомобілів, що знаходяться в даному регіоні, а також динаміку його зміни по різних періодах року $(j)$;

- середні напрацювання $\bar{I}_{j}$ на один автомобиле-заїзд на СТО;

- можлива зміна частки ринку $K_{j}$, що займає це підприємство в районі ділової активності;

- частка власників $\alpha$, які звертаються на СТО.

Комплексне врахування перелічених вище факторів дозволяє виконати прогнозування зміни середньодобової кількості звернень $\bar{N}_{\text {дj }}$ по різних видах робіт $(i)$, з урахуванням його сезонності $(j)$. При цьому $\bar{N}_{\text {дj }}$ для заданого конкретного $i$ можна представити у вигляді $[1$, с. 83]:

$$
\bar{N}_{\text {дj }}=\frac{N_{a в m} \times \bar{L}_{P} \times K_{\text {дj }} \times \alpha \times K_{j}}{\left(I_{j} \times D_{p}\right)},
$$


де $K_{\text {дj }}$ - коефіцієнт, що враховує сезонність річного пробігу автомобілів даного регіону (відображає долю річного пробігу, що припадає на $j$-й період року, при цьому $\sum_{j=1}^{n} K_{j}=1$;

$D_{p}$ - кількість днів роботи СТО за даний період.

Обсяг послуг СТО оцінюється через середній добовий обсяг робіт $\bar{t}_{\text {дij }}$, що визначається за формулою:

$$
\bar{t}_{\text {д }}=\bar{t}_{136 .} \times \bar{N}_{\text {д }},
$$

де $\bar{t}_{138 .}$ - математичне очікування трудомісткості одного звернення; $\bar{N}_{\text {д }}$ - математичне очікування добової кількості звернень.

3 метою спрощення отримуваної моделі, а також з урахуванням короткострокового періоду прогнозування, без втрати точності отримуваного результату, необхідно прийняти постійними наступні величини:

- середньорічний пробіг $\bar{L}_{P}$;

- коефіцієнт, що враховує динаміку посезонної зміни середнього річного пробігу $-K_{\text {дj; }}$;

- долю власників, що користуються послугами СТО в цьому регіоні $\alpha$;

- режим роботи СТО, що визначається кількістю днів роботи $D_{p}$ підприємства на даних періодах року;

- $\bar{t}_{138 . i j}-$ середню трудомісткість одного звернення.

Таким чином, прогнозування попиту на послуги СТО зводиться до оцінки зміни середньодобової кількості звернень на СТО, для чого необхідно розглянути динаміку зміни його складових (1). У загальному вигляді, методика прогнозування попиту на послуги СТО, визначається середньодобовою кількістю звернень на СТО, включає наступні етапи.

На першому етапі здійснюється розбиття річного інтервалу на рівні задані періоди. Збільшення міри розбиття підвищує трудомісткість проведення прогнозування $\mathrm{i}$, отже, його вартість, але при цьому зростає його точність. У якості прикладів подібного розбиття можна навести розбиття інтервалу по місяцях, по кварталах, по сезонах року.

На другому етапі, логічним продовженням попереднього, здійснюється збір відповідної статистичної інформації за наступними показниками (на основі періодів року, обраних на першому етапі): по добовій кількості звернень; по середньому напрацюванню на один автомобіле-заїзд на СТО; по середній трудомісткості одного звернення і т.д. За умови вибору в якості періодів кварталів (або сезонів року), збір статистичної інформації проводиться за середній місяць даного періоду.

На третьому етапі здійснюється збір інформації по загальній кількості автомобілів обслуговуваних моделей, що знаходяться в регіоні ділової активності даного підприємства (СТО), а також по середньорічному пробігу і його розподілу по сезонах (оцінюється шляхом проведення добровільного анонімного анкетування серед власників автомобілів, що обслуговуються на цьому підприємстві). Подібним способом визначається доля власників, що користуються послугами СТО по різних видах робіт.

Четвертий етап полягає в прогнозуванні зміни загальної кількості автомобілів, що знаходяться в даному регіоні, яке здійснюється 3 використанням логістичних залежностей, викладених в [2, с. 224]. Даний метод припускає оцінку прогнозування зміни кількості автомобілів, використанням такого показника, як насиченість регіону автомобілями на 1000 жителів:

$$
N_{\text {aвm }}=\frac{A \times n}{1000},
$$

де $N_{a в m}$ - кількість автомобілів в даному регіоні або районі ділової активності; $A$ - кількість жителів в районі ділової активності; $n$ - насиченість регіону, авт./1000 жителів.

3 метою прогнозування кількості автомобілів здійснюється збір відповідної інформації на ретроспективному періоді і визначається прогноз зміни насиченості по даних періодах.

Залежність насиченості $n$ від часу $t$ виражається диференціальним рівнянням виду $[1$, с. 85$]$ :

$$
\frac{d n}{d t}=q n\left(n_{\max }-n\right)
$$

де $n_{\max }$ - граничне значення насиченості; $q$ - коефіцієнт пропорційності. 
3 формули (4) випливає, що швидкість зростання насиченості $d n / d t$ пропорційна досягнутій насиченості $n$ і ненасиченості $\left(n_{\max }-n\right)$. Звідси видно, що при малих і великих значеннях $t$ швидкість зростання насиченості $n$ буде малою. Для заданого максимального (граничного) значення насиченості коефіцієнт пропорційності $q$ визначається на основі відомих значень насиченості регіону автомобілями на ретроспективному періоді (приклад - табл. 1).

Таблиця 1

Приклад початкових даних для здійснення прогнозування динаміки зміни насиченості регіону автомобілями (м. Київ)

\begin{tabular}{|c|c|c|c|}
\hline № & Період (рік) & Умовний номер періоду, $t$ & $\begin{array}{c}\text { Насиченість регіону } n_{j}, \\
\text { (автомобілів на 1000 жителів) }\end{array}$ \\
\hline 1 & 2017 & $t_{0}=0$ & 354 \\
\hline 2 & 2018 & $t_{1}=1$ & 362 \\
\hline 3 & 2019 & $t_{2}=2$ & 378 \\
\hline 4 & 2020 & $t_{3}=3$ & 384 \\
\hline 5 & 2021 & $t_{4}=4$ & 407 \\
\hline
\end{tabular}

Переписавши рівняння (2.6) у вигляді:

$$
\frac{\Delta n_{t}}{\Delta t}=q \times n_{\max } \times n_{t}-q \times n_{t}^{2}
$$

і прийнявши $\Delta t=1$ рік, запишемо [1, с. 86]:

$$
\Delta n_{t}=q \times n_{\max } \times n_{t}-q \times n_{t}^{2}
$$

Визначення коефіцієнта пропорціональності $q$ базується на використанні методу найменших квадратів, тобто [1, с. 87]:

$$
A=\sum_{t=1}^{m}\left(\Delta n_{t}-q \times\left(n_{\max } \times n_{t}-n_{t}^{2}\right)\right)^{2} \rightarrow \min
$$

Визначаючи похідну від $A$ по $q$ і прирівнюючи їі до нуля, отримуємо:

$$
\frac{d A}{d q}=2 \sum_{t=1}^{m}\left\{\left[\Delta n_{t}-q \times\left(n_{\max } \times n_{t}-n_{t}^{2}\right)\right] \times\left[-\left(n_{\max } \times n_{t}-n_{t}^{2}\right)\right]\right\}=0 \text { (8) }
$$

Остаточно отримуємо [1, с. 87$]$ :

$$
\sum_{t=1}^{m}\left\{\left[\Delta n_{t}-q \times\left(n_{\max } \times n_{t}-n_{t}^{2}\right)\right] \times\left[-\left(n_{\max } \times n_{t}-n_{t}^{2}\right)\right]\right\}=0
$$

Розв’язок цієї рівності дозволяє визначити шукане значення коефіцієнта пропорціональності $q$, тобто [1, с. 87]:

$$
q=\frac{\sum_{t=1}^{m}\left(\Delta n_{t} \times n_{t}^{2}\right)-n_{\max } \times \sum_{t=1}^{m}\left(\Delta n_{t} \times n_{t}^{2}\right)}{n_{\max }^{2} \times \sum_{t=1}^{m} n_{t}^{2}-2 \times n_{\max } \times \sum_{t=1}^{m} n_{t}^{3}+\sum_{t=1}^{m} n_{t}^{4}}
$$

У свою чергу, розв'язок рівняння виду:

$$
\frac{d n}{n\left(n_{\max }-n\right)}=q d t
$$

При заданому $n_{\max }$ і обчисленому значенні $q(10)$, з урахуванням вимоги проходження функції $n$ $=f(t)$ через останню точку $n_{\mathrm{m}}$ (в даному прикладі через $n_{\mathrm{m}}=n_{4}$, табл. 1$)$ ретроспективного періоду для $t=\mathrm{m}$, дозволяє, після нескладних перетворень, остаточно отримати залежність зміни насиченості населення легковими автомобілями від часу, тобто [1, с. 88$]$ :

$$
n_{t}=\frac{n_{\text {max }} n_{\mathrm{m}}}{n_{\mathrm{m}}+\left(n_{\max }-n\right) \times \exp \left[-q n_{\max }(t-\mathrm{m})\right]}
$$

Розв'язок рівняння (12) відносно фактора часу $t$ дозволяє оцінити часовий інтервал (лаг) виходу насиченості населення легковими автомобілями на задане граничне (чи близьке до нього) значення насиченості: 
Результати прикладу прогнозованої зміни насиченості населення легковими автомобілями для м. Києва представлені на рис. 1.

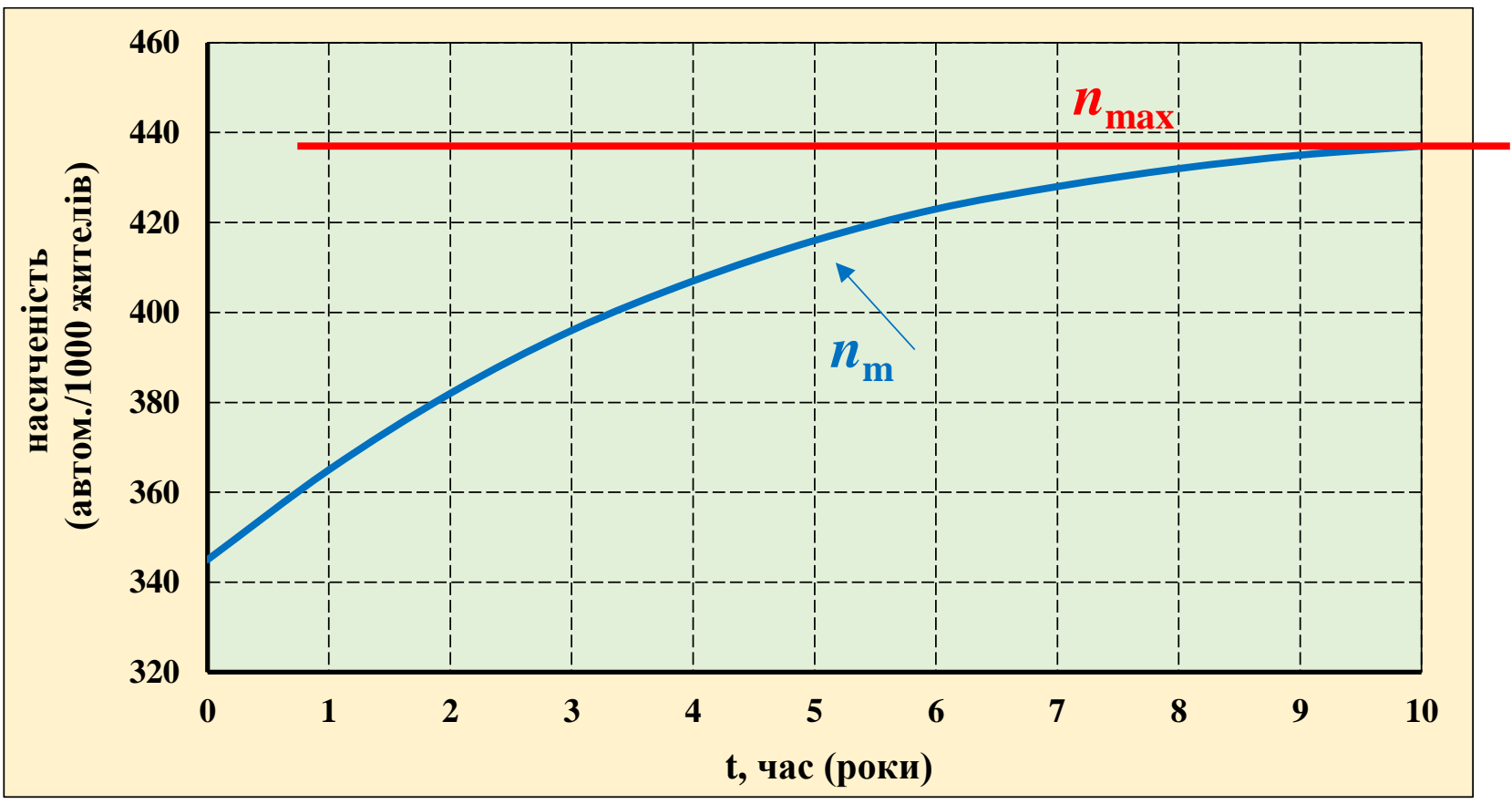

Рис. 1. Прогноз насиченості населення легковими автомобілями (м. Київ)

П’ятим етапом $є$ прогнозування частки ринку, займаної підприємством, що може бути здійснено на основі використання математичного апарату кореляційно-регресійного аналізу. При цьому визначення частки, що займає дане підприємство на ринку для кожного з часових періодів, що задаються на першому етапі, виконується з рівності [1, с. 88]:

$$
K_{j}=\frac{\bar{N}_{\text {д }} \times I_{j} \times D_{p}}{N_{a в m} \times \bar{L}_{p} \times K_{\text {дj }} \times \alpha}
$$

Згладжування отриманого часового ряду обчисленням ковзного середнього [3-5] визначається або по трьох, або по п'яти точках, відповідно, за допомогою (15) або(16) [1, с. 90]:

$$
\begin{aligned}
\bar{K}_{j} & =\frac{K_{j-1}+K_{j}+K_{j+1}}{3} \\
\bar{K}_{j} & =\frac{K_{j-2}+K_{j-1}+K_{j}+K_{j+1}+K_{j+2}}{5}
\end{aligned}
$$

Недоліком використання цього методу є те, що пропадають, відповідно, одна або дві, відповідно, перші і останні точки даного часового ряду. Для їх визначення використовуються наступні вирази: для ковзного середнього по трьох точках - вирази (17) i (18), для ковзного середнього по п’яти точках - формули (19)-(20), відповідно [1, с. 90]:

$$
\begin{aligned}
& \bar{K}_{1}=\frac{2 K_{1}+K_{2}}{3} \\
& \bar{K}_{n}=\frac{2 K_{n}+K_{n-1}}{3} \\
& \bar{K}_{1}=\frac{\left(3 K_{1}+2 K_{2}+K_{3}\right)}{6} \\
& \bar{K}_{2}=\frac{2 K_{2}+K_{3}}{3}
\end{aligned}
$$




$$
\begin{aligned}
& \bar{K}_{n-1}=\frac{2 K_{n-1}+K_{n-2}}{3} \\
& \bar{K}_{n}=\frac{\left(3 K_{n}+2 K_{n-1}+K_{n-2}\right)}{6}
\end{aligned}
$$

Використання цих виразів дозволяє отримати згладжений ряд з незміщеним середнім рівнем. Результатом використання методів «ковзного середнього» є зниження впливу «шумової» складової i, як наслідок, отримання більш згладженого ряду, який використовується для подальшого отримання регресійних залежностей.

Для визначення зміни частки $K_{j}$, що займає дана СТО на ринку, для кожного з часових періодів доцільно використати моделі з адитивним трендом (у виразах, представлених нижче, передбачається, що прогнозування ведеться по якому-небудь одному виду робіт, тому індекс $i$ для спрощення не вказується):

$$
K_{j}=K_{t}+K_{S}+E
$$

Складові виразу (23) мають наступний вигляд:

$K_{t}$ - трендове значення:

$$
K_{t}=a_{t}+b_{t} \times t_{j}
$$

де $a_{t}, b_{t}$ - коефіцієнти лінійного рівняння регресії, що визначаються за методом найменших квадратів [1, с. 91]:

$$
\begin{aligned}
& b_{t}=\frac{\sum_{j=1}^{n} t_{j} \times \sum_{j=1}^{n} K_{j}-n \sum_{j=1}^{n} t_{j} \times K_{j}}{\left(\sum_{j=1}^{n} t_{j}\right)^{2}-n \sum_{j=1}^{n} t_{j}^{2}} \\
& a_{t}=\frac{1}{n}\left(\sum_{j=1}^{n} K_{j}-b \sum_{j=1}^{n} K_{j}\right),
\end{aligned}
$$
періодів;

де $t_{j}$ - умовний порядковий номер часового періоду; $n$ - загальна кількість даних тимчасових

$K_{S j}$ - сезонна складова, що визначається за допомогою методів гармонійного аналізу [6, с. 36]:

$$
K_{S j}=a_{0}+a_{1} \cos \frac{2 \pi t_{j}}{L}+b_{1} \sin \frac{2 \pi t_{j}}{L},
$$

де $a_{0}, a_{1}, b_{1}$ - коефіцієнти рівняння гармонійних коливань, що визначаються:

$$
\begin{gathered}
a_{0}=\frac{\sum_{j=1}^{n} K_{j}}{n}, \\
a_{1}=\frac{2}{n} \sum_{j=1}^{n} K_{j} \cos \frac{2 \pi t_{j}}{L}, \\
b_{1}=\frac{2}{n} \sum_{j=1}^{n} K_{j} \sin \frac{2 \pi t_{j}}{L},
\end{gathered}
$$

де $L$ - період коливань; $E$ - випадкова («шумова») компонента.

Отримання кінцевого рівняння регресії здійснюється шляхом підсумовування рівняння лінійного тренду і рівняння гармонічних коливань:

$$
K_{j}=a+b t_{j}+a_{1} \cos \frac{2 \pi t_{j}}{L}+b_{1} \sin \frac{2 \pi t_{j}}{L},
$$

де $a=a_{t}+a_{0}$.

Отримання шуканих значень $K_{j}$ для прогнозних періодів здійснюється на основі продовження рівняння тренду на майбутні періоди. Оцінка достовірності отриманого рівняння регресії здійснюється на основі використання наступних показників [7; 8]: 
1) коефіцієнта множинної детермінації $R$, за яким оцінюється наближення отриманого рівняння регресії до експериментальних даних;

2) $F$-критерію Фішера, за яким оцінюється достовірність отриманого рівняння регресії;

3) середнього абсолютного відхилення [8, с. 42], яке визначається за (32) (при цьому MAD має бути якомога меншим):

$$
M A D=\frac{\sum\left|E_{j}\right|}{n},
$$

де $E_{j}-$ значення випадкової («шумовий») складової, яке визначається відніманням з фактичних (експериментальних) даних значень, що отримуються за допомогою рівняння регресії;

$n$ - кількість даних часових періодів.

4) середньоквадратичної похибки [8, с. 42], яка визначається як:

$$
M S E=\frac{\sum E_{j}^{2}}{n}
$$

5) середньоабсолютної похибки прогнозування [8, с. 42], яка визначається як:

$$
\text { MAPE }=\frac{1}{n} \sum_{j=1}^{n} \frac{\left|y_{j}-y\right|}{y_{j}} \times 100,
$$

Цей показник, як правило, використовується при порівнянні точності прогнозів різнорідних об’єктів прогнозування, оскільки характеризує відносну точність прогнозу. 3 (34) можна помітити, що при фактичному значенні $y=0$, MAPE стає нескінченною. На практиці значення $y=0$ пропускають, зменшуючи при цьому величину $n$ на кількість пропусків. Інтерпретація отриманих різних значень $M A P E$ наведена в табл. 2.

Таблиця 2

Інтерпретація отриманих значень $M A P E$

\begin{tabular}{|c|l|}
\hline MAPE, \% & \multicolumn{1}{|c|}{ Інтерпретація } \\
\hline$<10$ & Висока точність \\
\hline $10-20$ & Хороша точність \\
\hline $20-50$ & Задовільна точність \\
\hline$>50$ & Незадовільна точність \\
\hline
\end{tabular}

\section{ОБГОВОРЕННЯ РЕЗУЛЬТАТІВ ДОСЛІДЖЕНЬ}

Прогнозування попиту на послуги СТО зводиться до оцінки зміни середньодобової кількості звернень на СТО, для чого була розглянута динаміка зміни його складових (1).

Недоліком використання цього методу є те, що пропадають, відповідно, одна або дві, відповідно, перші і останні точки даного часового ряду. Для їх визначення використовуються наступні вирази: для ковзного середнього по трьох точках - вирази (17) i (18), для ковзного середнього по п'яти точках - формули (19)-(20), відповідно [1, с. 90]:

\section{ВИСНОВКИ}

Для прогнозування попиту на послуги СТО, було розглянуто динаміку зміни його складових (1). У загальному вигляді, методика прогнозування попиту на послуги СТО, визначається середньодобовою кількістю звернень на СТО.

Наведені методи дозволяють з достатньою точністю зробити необхідні розрахунки, пов'язані 3 прогнозуванням попиту на послуги СТО, що $є$ необхідною умовою для забезпечення довгострокових перспектив існування підприємства.

\section{ПЕРЕЛІК ДЖЕРЕЛ ПОСИЛАННЯ}

1.Чернышов А.Е. Комплексная оценка эффективности функционирования автосервисных предприятий: на примере СТО легковых автомобилей :. Москва, 2005. 217 с.

2. Напольский Г.М. Технологическое прозктирование автотранспортних предприятий и станций технического обслуживания-М.: Транспорт, 1993. - 272 с.

3. Математические методы прогнозирования экономических показателей : учеб. пособие / А.P. Саянова и др. Уфа, 2000. 128 с.

4. Теория статистики с основами теории вероятностей : учеб. пособие. / Елисеева И.И и др; под ред. И.И. Елисеевой. Москва : ЮНИТИ-Дана, 2001. 446 с. 
5.Бедняк М.Н., Франчук Д.Н., Определение оптимальной производительности станции диагностики. Сб. «Основные направления автоматизации систем управления автомобильным транспортом» К., «Знание»,1972.

6. Бедняк М.Н. Моделирование процессов технического обслуживания и ремонта автомобилей. Киев : Вища школа, 1983. 131 с.

7. Марков О.Д. Станции технического обслуживания автомобилей. - К.: Кондор, 2008. - 536 с.: 16 цветн. ил.

8. Марков О.Д. Обслуговування клієнтів автосервісу: Навчальний посібник / О.Д. Марков, Н.В. Веретельникова. - К.: Каравела, 2015.

9. Seo K.K. Managerial economics: text, problems and short cases. 7 ed. 1991. Boston, Business \& Economics. 643 p.

10. Інтернет ресурси «Положення про технічне бслуговування і ремонт дорожніх транспортних засобів (ДТЗ)» .

11. Ринок послуг автосервісу України 2011 році/2011/україна/автосервіс:

http://autoshkola.net/articles/article-16/

\section{REFERENCES}

1. Chernyshov AE Comprehensive assessment of the efficiency of car service enterprises: on the example of HUNDRED cars: Moscow, 2005. 217 p.

2. Напольский Г.М. Technological projection of motor transport enterprises and service stations-M .: Transport, 1993. - $272 \mathrm{p}$.

3. Mathematical methods for forecasting economic indicators: textbook. allowance / A.R. Sayanova et al., Ufa, 2000. 128 p.

4. Theory of statistics with the basics of probability theory: textbook. allowance. / Eliseeva II and others; under ed. I.I. Елисеевой. Moscow: UNITI-Dana, 2001. 446 p.

5. Bednyak MN, Franchuk DN, Determination of the optimal performance of the diagnostic station. Sat. "The basic directions of automation of systems of management of motor transport" K., "Knowledge", 1972. $131 \mathrm{p}$

6. Bednyak MN Modeling of processes of maintenance and repair of cars. Kiev: Higher School, 1983.

7. Markov OD Car maintenance stations. - К .: Кондор, 2008. - 536 с .: 16 цветн. il.

8. Markov OD Car service customer service: Textbook / OD Markov, NV Веретельникова. - К .: Каравела, 2015.

9. Seo K.K. Managerial economics: text, problems and short cases. 7 ed. 1991. Boston, Business \& Economics. 643 p.

10. Internet resources "Regulations on maintenance and repair of road vehicles (accidents)".

11. The market of car service services of Ukraine in 2011/2011 / ukraine / car service:

http://autoshkola.net/articles/article-16/

\section{P.Godovanyuk. Mathematical model of forecasting services for car services}

The method of drawing up of mathematical model of forecasting of demand for car service is offered in the work.

The development of appropriate models is an important task. The following factors were taken into account during the development:

- it is possible to change the total number of cars Navt, which are in the area of business activity of the service station;

- intensity of operation, ie the average annual mileage of cars in the region, as well as the dynamics of its change at different times of the year (j);

- average operating time per car-arrival at the service station;

- possible change in market share $\mathrm{Kj}$, which occupies this company in the area of business activity;

- the share of $\alpha$ owners who apply to the service station.

Comprehensive consideration of the above factors allows you to predict changes in the average daily number of applications for different types of work (i), taking into account its seasonality (j).

In order to simplify the obtained model, as well as taking into account the short-term forecasting period, without losing the accuracy of the obtained result, the following constant values were adopted:

- average annual mileage; 
Kdj;

- coefficient that takes into account the dynamics of seasonal changes in the average annual mileage -

- the share of owners who use the services of service stations in this region $\alpha$;

- the mode of operation of the service station, which is determined by the number of working days of the enterprise at these periods of the year;

- - the average complexity of one application.

Thus, forecasting the demand for service stations is reduced to estimating the change in the average daily number of calls to the service station, for which the dynamics of changes in its components was considered (1). In general, the method of forecasting the demand for service stations is determined by the average daily number of calls to the service station, and includes five stages.

The disadvantage of using this method is that missing, respectively, one or two, respectively, the first and last points of this time series. To determine them, the following expressions are used: for the moving average of three points - expressions (17) and (18), for the moving average of five points - formulas (19) (20), respectively [1, p. 90]:

Keywords :, car services, reconstruction, efficiency, mathematical model, optimization.

ГОДОВАНЮК Петро Дмитрович, кандидат технічних наук, Національний транспортний університет, Київ, Україна, pgodovanuk04@gmail.com, orcid.org/0000-0001-6331-8698

Petro GODOVANYUK, Candidate of Technical Sciences, National Transport University, Kyiv, Ukraine,pgodovanuk04@gmail.com,orcid.org/0000-0001-6331-8698

DOI 10.36910/automash.v2i17.635 